\title{
Usefulness of the Pipeline Embolic Device for Large and Giant Carotid Cavernous Aneurysms
}

\author{
Shigeru Miyachi, MD', Ryo Hiramatsu, MD², Hiroyuki Ohnishi, MD³, \\ Ryokichi Yagi, MD², Toshihiko Kuroiwa, MD²
}

Purpose: Conventional coil embolization for large carotid cavernous aneurysms (CCAs) has limited utility due to its inability to prevent recurrences and reduce mass effect. Trapping of the parent artery may have a risk of ischemic complications due to intracranial perfusion disorders. We successfully treated 24 patients with large CCAs using a flow diverter (Pipeline ${ }^{\mathrm{TM}}$ embolic device: PED), and this report discusses the safety and efficacy of this method.

Materials and Methods: Twenty four patients (23 females, mean age 71.5 years old) with large CCAs, including 6 giant CCAs, were treated with a PED over three years. Under sufficient dual antiplatelet management, the PED was deployed over the orifice of the aneurysm. Two patients required multiple telescoping stents. Clinical and radiological states were checked with MRI at 1, 3 and 6 months post-surgically. Angiographic follow-up was performed at 6 months.

Results: In all patients, PED was appropriately deployed. Stagnation of contrast with eclipse signs was observed post-angiogram in 21 cases. One patient requiring 5 telescoping stents experienced temporary ischemic symptoms. Fourteen patients experienced improvement of ocular motor impairment deficiency, including 6 patients who recovered. Angiograms at 6 months follow-up showed complete occlusion in $63 \%$ (12/19) of patients, and MRI showed reduction of aneurysm volume in $89 \%(17 / 19)$ of patients.

Conclusion: Flow diverters for large CCAs showed promising clinical and radiological efficacy. They can shrink the aneurysm and improve symptoms without sacrificing the parent artery. It will be necessary to summarize the cases and to verify the long-term results.

Key Words : Carotid cavernous aneurysm; Endovascular treatment; Flow diverter;

Pipeline ${ }^{T M}$ embolic device

'Neuroendovascular Therapy Center, Aichi Medical University, Nagakute, Aichi, Japan

2Department of Neurosurgery and Neuroendovascular Therapy, Osaka Medical College, Takatsuki, Osaka, Japan

${ }^{3}$ Ohnishi Neurosurgical Hospital, Akashi, Hyogo, Japan

Received July 19, 2017; Revised July 26, 2017; Accepted July 27, 2017.

Correspondence to: Shigeru Miyachi, MD, PhD, Department of Neurosurgery and Neuroendovascular Therapy, Aichi Medical University, 1-1 Yazakokarimata, Nagakute, 480-1195 Aichi, Japan.

Tel. +81.561.62.3311 Fax.+81.561.63.2879 E-mail: miyachi.shigeru.752@mail.aichi-med-u.ac.jp

This is an Open Access article distributed under the terms of the Creative Commons Attribution Non-Commercial License (http://creativecommons.org/licenses/by-nc/3.0) which permits unrestricted non-commercial use, distribution, and reproduction in any medium, provided the original work is properly cited. 
Large and giant carotid cavernous aneurysms (CCAs) tend to cause mass effect, manifesting ocular motor nerve palsy and trigeminal neuralgia. They have been treated with simple coil packing with balloon or stent assist techniques for such symptomatic aneurysms. However, these methods are not always effective against the decompression of cranial nerves because of the filled coil mass in the sac, and the symptoms occasionally worsen due to regrowth of the aneurysm. Parent artery occlusion has been thought of as the most effective way to achieve recovery from cranial nerve palsy due to large CCAs [1]. It can stop all inflow to the aneurysm in exchange for the loss of one carotid artery. However, in cases of poor collaterals, extraintracranial arterial bypass surgery should be required.

Flow diversion (FD) has been introduced as an alternative option for treating large cerebral aneurysms. FD can promote aneurysm occlusion through a process of endoluminal reconstruction of the parent artery and by rectifying blood flow away from the aneurysm sac [2]. Specifically, positive results of a Pipeline ${ }^{\mathrm{TM}}$ embolization device (PED) (Medtronic/ Covidien, Irvine, CA, USA) have been demonstrated in several recent series [2-5]. In the present study, we review our case series of patients treated with PED, and discuss the efficacy and safety of the flow diverter by comparison with other conventional treatment options.

\section{MATERIALS AND METHODS}

\section{Patient and aneurysm profile}

An endovascular approach was used to treat 59 patients with unruptured large and giant CCAs between December 2012 and December 2016 at Nagoya University and Osaka Medical College. After obtaining institutional review board approval from each institution, we searched our prospectively maintained database for all patients with unruptured CCAs. Twenty four aneurysms in 24 patients ( 23 women and 1 man; 40-86 years old; mean age 71.5 years) were treated with PED. We retrospectively reviewed the patients' medical charts to determine the patient profiles, aneurysm characteristics, procedural specifics, and procedural complications. Only clinically relevant procedural complications are reported here. Radiological studies, including angiography, MRI, and CT were carefully reviewed pre- and postoperatively and at 6 months follow-up.

Of the 24 aneurysms, 16 were located on the right side, and the mean max. dia. was $19.4 \mathrm{~mm}$. There were 18 large aneurysms and six giant aneurysms. Fourteen patients had a single aneurysm, and six patients had another aneurysm in addition to a CCA. Eighteen patients suffered ocular motor palsy, and 1 patient suffered ocular pain. Six patients were asymptomatic.

All 24 patients were pre-medicated with anti-platelet agents for 7 days before the intervention. The patients were pre-loaded with $75 \mathrm{mg}$ of clopidogrel and $100 \mathrm{mg}$ of aspirin daily. Treatment was performed with an initial 5,000 IU heparin bolus and the intraoperative maintenance of an activated clotting time of two times of the patient's baseline value. Anti-platelet function was checked preoperatively with VerifyNow ${ }^{\circledR}$ (Medicos-Hirata, Osaka) for all patients, and further anti-platelet agents were loaded for hypo-responders (PRU>250). Heparin was discontinued at the conclusion of the procedure. Dual antiplatelet therapy was continued for $\geq 6$ months after the procedure.

\section{Deployment of PED}

With the patient under general anesthesia, a 6 Fr. super-long sheath (Shuttle ${ }^{\mathrm{TM}}$ sheath, Cook Medical, Bloomington, IN) and a coaxial 5 Fr. or 6 Fr. distal access catheter (Navien ${ }^{\mathrm{TM}}$, Medtronic/ Covidien) were placed in the ICA, and a microcatheter (Marksman ${ }^{\mathrm{TM}}$, Medtronic/ Covidien) for stent delivery was placed distal to the aneurysm. A PED was carefully deployed using the unsheath or "center \& push" method [6]. After the stent was deployed, vessel wall apposition was remedied with a micro-balloon (Hyperform; Medtronic/ Covidien) angioplasty in all cases, and the state of expansion of the PED was confirmed on conebeam CT. The final angiogram was checked to determine the reduction of the inflow to the aneurysmal sac (expressed as an eclipse sign) and intra-stent rectification of the carotid flow. We used a single stent in all cases except for one case that required telescoping overlapped stents because of the insufficient effect of the flow diverter on the single stent. No coils were placed in the aneurysmal sac.

\section{Clinical and radiological follow-up}

The primary clinical outcome was the status of cranial nerve deficits produced by the mass effect. The final clinical status was assessed at the 6-month followup. The registered complications were ischemic events, hemorrhagic stroke, aneurysm rupture and increased mass effect. We collected clinical outcomes at the last available follow-up from follow-up notes of the attending physician and classified them using the modified Rankin Scale.

We classified the occlusion state just after the 


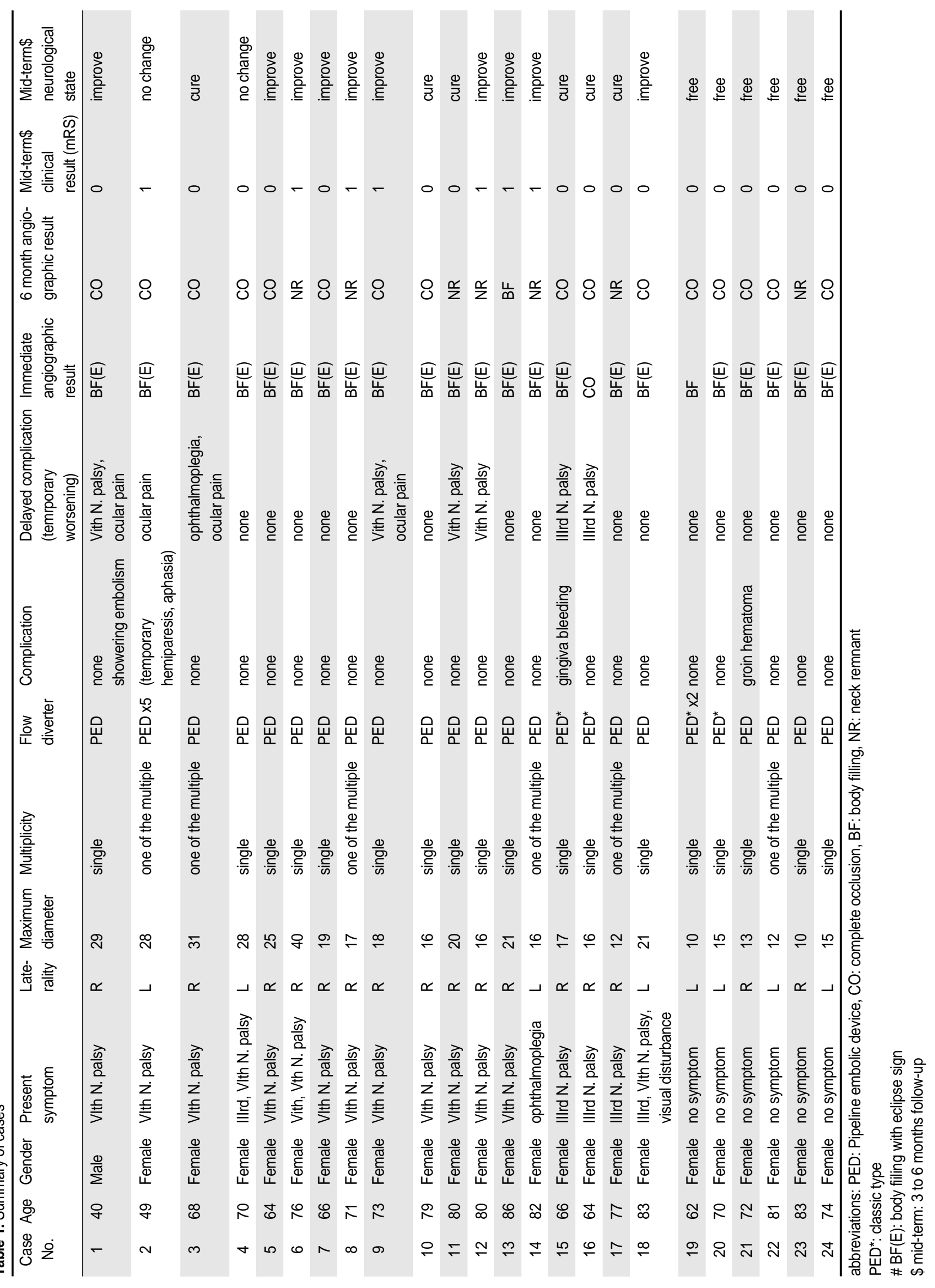


treatment into three categories according to the Roy and Raymond scale [7]: complete occlusion (CO) including no visualization of the aneurysmal sac as well as the parent artery occlusion; neck remnant (NR); and body filling (BF) with the remnant sac. Although no immediate occlusion of the aneurysmal sac was found in most patients, the rectifying effects were recognized as a blurred or partial opacification of the aneurysm due to the subtraction of remaining stagnated contrast in the sac expressed as an "eclipse sign".

A radiological follow-up for each patient (digital subtraction angiography [DSA] or magnetic resonance angiography [MRA]) was scheduled for 3-6 months after treatment. Any aneurysms observed at the 6month follow-up were classified with the same scale again, and aneurysms that displayed a decreasing percentage of occlusion ( $>10 \%)$ on follow-up angiography were considered recurrent.

\section{RESULTS}

The patient summary is shown in Table 1, and profiles and results are shown in Table 2. There was only one case of immediate aneurysm obliteration, and all of the other aneurysms were filled to some degree (regarded as body filling) and showed the typical eclipse sign, except for two cases.

At the 6-month follow-up, 16 of the 24 aneurysms were found to be completely obliterated, and among the five remaining aneurysms a small leak from the PED was observed at the neck in four, and major body filling remained in one (Case 13). On MRI, follow-up some degrees of size reduction were observed in all aneurysms.

Among the 18 symptomatic patients with ocular motor nerve deficits or visual disturbances, an improvement of symptoms before 6 postoperative months was obtained in 16 patients, including cures in 6 patients.

Newly developed or worsened ocular motor nerve palsy was temporarily observed in 7 patients. Oculomotor palsy was observed in addition to abducens palsy in five patients, ocular motor nerve palsy was newly developed in three patients, and worsening of existing abducens palsy was found in two patients. The timing of the manifestations of these symptoms occurred at an approximately 3 -week interval, and all of them disappeared or improved within 3 months.

There was one procedure-related complication with ischemic events; a case of telescoping stent due to the complicated procedure (Case 2). Temporary hemiparesis and aphasia completely resolved at one month. We encountered two asymptomatic hemorrhagic complications, probably due to the hyper-response of antiplatelet agents.

\section{Representative cases}

Case 1: A giant aneurysm of complete occlusion (Case No. 1)

This 40-year-old male was suffering from progressive

Table 2. Summary of the Patient and Aneurysm Profile and the Treatment Results

\begin{tabular}{|c|c|c|}
\hline \multicolumn{2}{|c|}{ Total aneurysm number (Patient No.) } & $24(24)$ \\
\hline \multicolumn{3}{|l|}{ Patient profile } \\
\hline age & mean (range) & $.5(40-86)$ \\
\hline gender & $\mathrm{M} / \mathrm{F}$ & $1: 23$ \\
\hline \multirow[t]{5}{*}{ symptom } & double vision & 18 \\
\hline & visual disturbance & 1 \\
\hline & ocular pain & 1 \\
\hline & other symptoms & 1 \\
\hline & no symptoms & 6 \\
\hline \multicolumn{3}{|l|}{ Aneurysm profile } \\
\hline side* & $\mathrm{R} / \mathrm{L}$ & $16: 8$ \\
\hline max. diameter (mm) & mean (range) & $.4(10-40)$ \\
\hline \multirow[t]{2}{*}{ size } & large (10 24 mm) & 18 \\
\hline & giant $(25 \mathrm{~mm} \leqq)$ & 6 \\
\hline \multirow[t]{2}{*}{ multiplicity } & single & 18 \\
\hline & multiple (mirror) & $6(1)$ \\
\hline \multirow{3}{*}{$\begin{array}{l}\text { Treatment summary } \\
\text { method }\end{array}$} & & \\
\hline & flow diverter (single) & 22 \\
\hline & flow diverter (telescoping) & 2 \\
\hline \multirow[t]{5}{*}{ complications } & ischemic events (temporary) & 1 \\
\hline & ischemic events (permanent) & 0 \\
\hline & hemorrhagic events & 0 \\
\hline & aneurysm rupture & 0 \\
\hline & increased mass effect & 8 \\
\hline \multirow[t]{4}{*}{ radiological result } & complete occlusion (CO) & 1 \\
\hline & neck remnant (NR) & 0 \\
\hline & body filling (BF) & 1 \\
\hline & body filling with eclipse sign & 22 \\
\hline \multirow{5}{*}{$\begin{array}{l}\text { Outcome on } 6 \text { months } \\
\text { neurological state }\end{array}$} & & \\
\hline & no deficit (complete recovery) & y) 12 \\
\hline & improve & 10 \\
\hline & no change & 2 \\
\hline & worsen & 0 \\
\hline \multirow[t]{2}{*}{$\mathrm{mRS}$} & 0 & 17 \\
\hline & 1 & 7 \\
\hline \multirow[t]{4}{*}{ radiological state } & complete occlusion (CO) & 16 \\
\hline & neck remnant (NR) & 7 \\
\hline & body filling (BF) & 1 \\
\hline & recurrence (retreatment) & 0 \\
\hline
\end{tabular}


right abducens palsy. He had a giant CCA protruding laterally at the right side (Fig. 1A). A PED $(4.0 \times 25$ $\mathrm{mm}$ ) was successfully deployed with a marked eclipsed sign (Fig. 1C). His symptoms were resolved at the 3month follow-up, and the angiogram taken at 6 months showed complete occlusion of the aneurysm (Fig. 1D). The aneurysm was found to have shrunk in the MRI (Fig. 1E, F).

\section{Case 2: A giant aneurysm requiring a telescoping stent (Case No. 2)}

A 48-year-old female had suffered from progressive double vision and headache for 4 years. She presented with total abducens nerve palsy on the left side. Left carotid angiogram disclosed a no-necked giant CCA and another tandem aneurysm on the near proximal side (Fig. 2A, B). Five PEDs were connected with partial overlapping to cover the neck of both aneurysms in two stages (Fig. 2C). The final angiogram showed a significant flow diversion effect with a typical eclipse sign. However, she suffered from right hemiparesis and mild aphasia for 1 month because of the long, complicated procedures. Post-MRI showed multiple small ischemic lesions due to the showered thromboemboli (Fig. 2D). Her symptoms remained at 6 months, but the aneurysm was completely resolved on the angiogram (Fig. 2E)

\section{Case 3: A case of remaining neck on the follow-up (Case No. 11)}

This 80 -year-old female complained of double vision due to complete abducens and mild oculomotor palsy beginning 6 months ago. She had a large CCA at the right side (Fig. $3 \mathrm{~A})$ and underwent a PED $(4.0 \times 25$ $\mathrm{mm}$ ) deployment (Fig. 3B). The angiogram obtained just after the treatment demonstrated a typical eclipse sign, suggesting stagnating intra-aneurysmal flow (Fig. 3C). Two weeks later, her ocular symptoms had worsened to complete oculomotor palsy with severe ocular pain. Her symptoms gradually improved due to steroid medication and completely subsided 3 months later. A follow-up angiogram at 6 months showed that the PED had sunk into the aneurysmal sac due to the loss of an anchoring effect associated with shortening of the distal side, and the original pathway was left with a remnant neck (Fig. 3D, E).
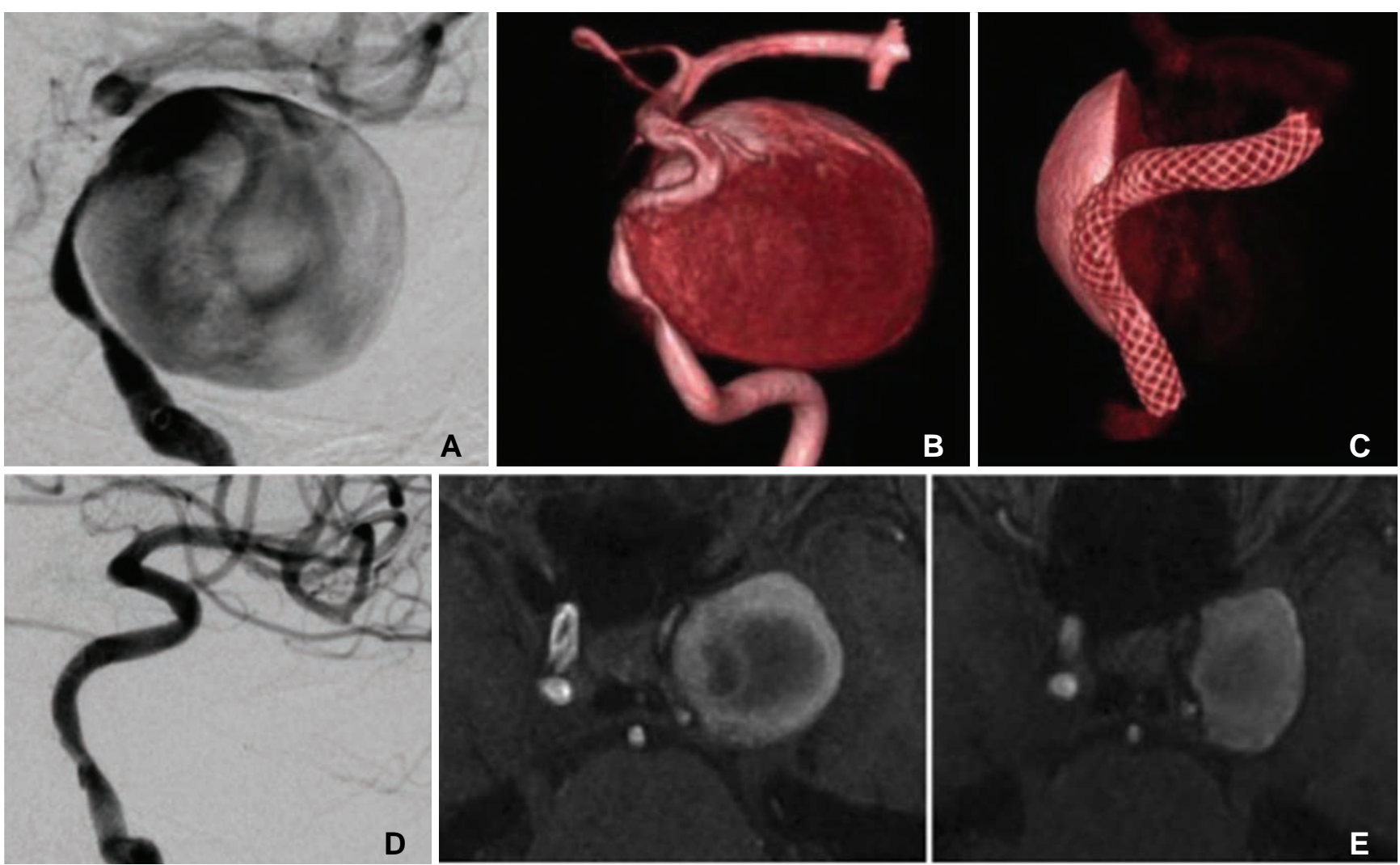

Fig. 1. A giant aneurysm of complete occlusion (Case No. 1). Right carotid angiogram showed a giant CCA protruding laterally (A, B). After deploying a PED $(4.0 \times 25 \mathrm{~mm})$, the neck cone-beam CT revealed a marked eclipsed sign (C). Angiogram taken at 6 months showed complete occlusion of the aneurysm (D). MRI demonstrated the shrinkage of the aneurysm (E: right: just after the treatment, left: 6 months follow-up). 

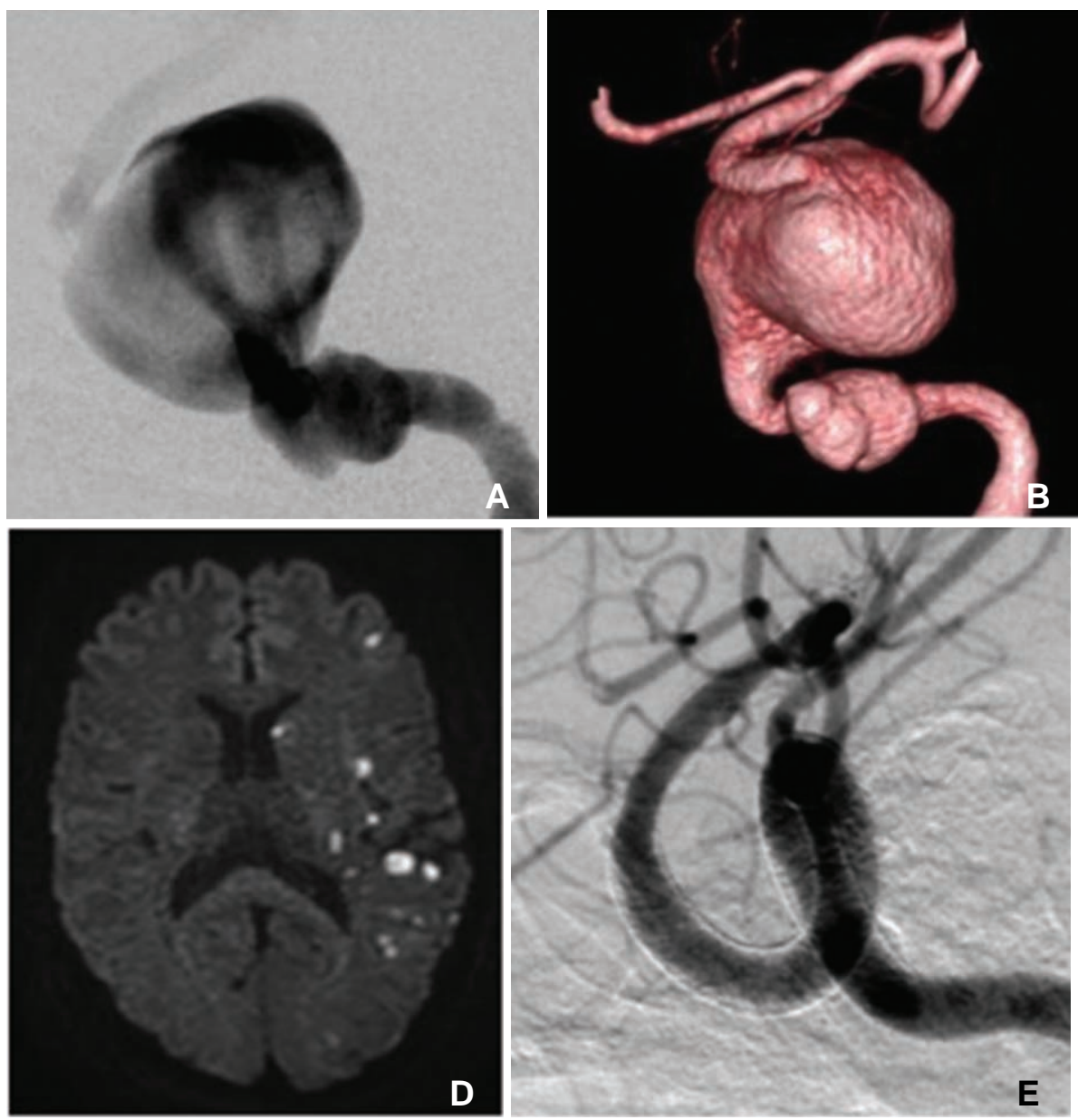

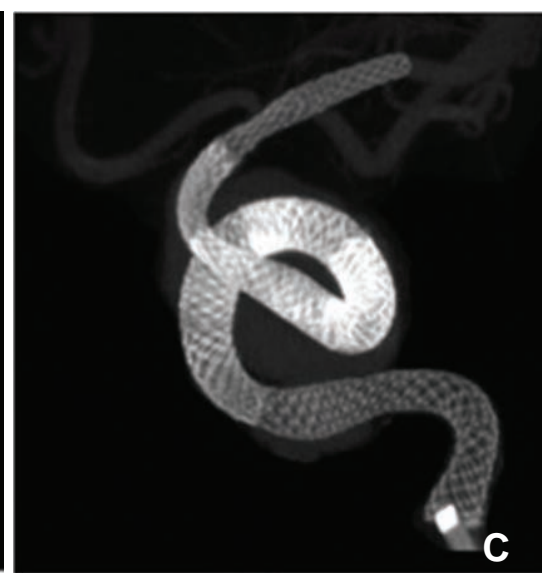

Fig. 2. A giant aneurysm requiring telescoping stent (Case No. 2). Left carotid angiogram showed a dysplastic, giant CCA without a neck and another tandem aneurysm on the near proximal side (A, B). Five PEDs were connected with partial overlapping to cover the neck of both aneurysms on two stages (C). Post-MRI showed multiple small ischemic lesions (D). Angiogram taken at 6 months showed complete occlusion of the aneurysm (E).

\section{DISCUSSION}

A flow diverter is a key device for large and giant cerebral aneurysms. The Pipeline embolic device (PED) is the only flow diverter device approved in Japan. PED, which closes the orifice with a dense woven mesh and, while conserving the parent artery, promotes natural internal thrombolization, is a device developed based on a completely different concept compared to coil embolization [3, 4].

The efficacy of flow diverters has been demonstrated in previous studies. Puffer et al. [7] reported that 36\% of the patients in their series showed procedure-related or delayed complications but no clinical sequelae [8]. The mortality rate associated with flow diverter use was $0 \%-4 \%$ in many studies $[2-5,8-13]$. The rate of occlusion of an aneurysm with a flow-diverting stent is higher than that of the usual coiling method with adjunctive techniques $[12,13]$. A multicenter study showed $71-86 \%$ complete occlusion rates, and no recurrence $[14,15]$. Ocular motor palsy symptoms were relieved within 3 months in more than $90 \%$ of symptomatic patients in our series. However, seven of 18 symptomatic patients showed temporary deterioration of ocular motor nerve palsy. This strange course may be due to the strong inflammatory reaction of the aneurysmal wall along the progressive thrombosis in the aneurysmal sac. Thrombosis leads to a strong mural inflammation of the blood vessel. Such a vital reaction is commonly found at the connective tissue around thrombosed veins as well as in embolized experimental aneurysms [16]. Inflammation that extends around the aneurysmal sac can affect the neighboring cranial nerves, resulting in the deterioration or loss of their function. This mechanism is supported by MRI findings of luminal enhancement of the aneurysm wall and the dramatic effects of steroid administration [17].

In our series, this deterioration was encountered approximately two weeks after the deployment of PED. According to our cohort study comparing another treatment option, stent-assisted saccular coil packing [6], such manifestations tended to be more delayed in PED cases than in cases with coil embolization. We posit that this time lag is related to the differences in 

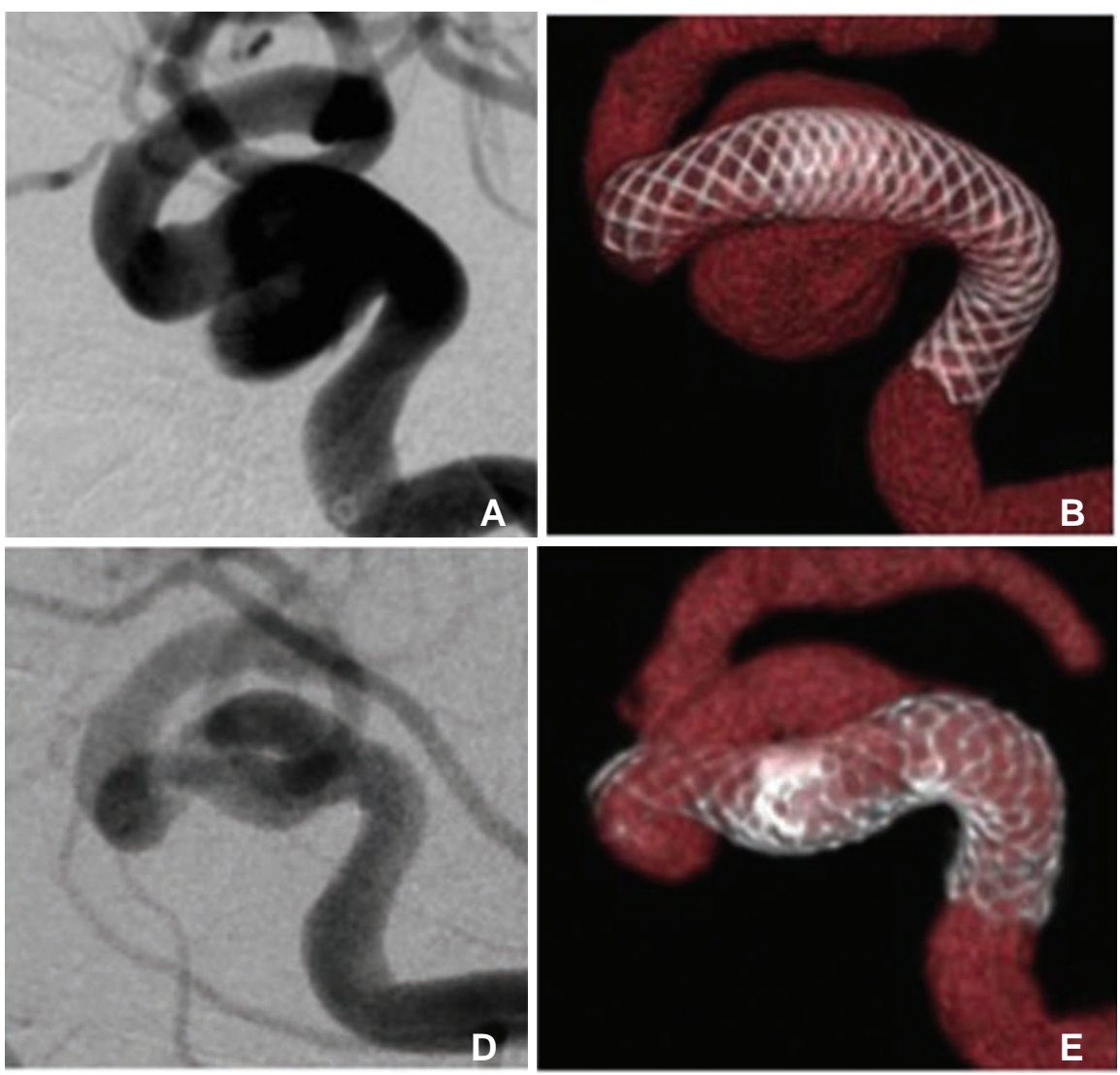

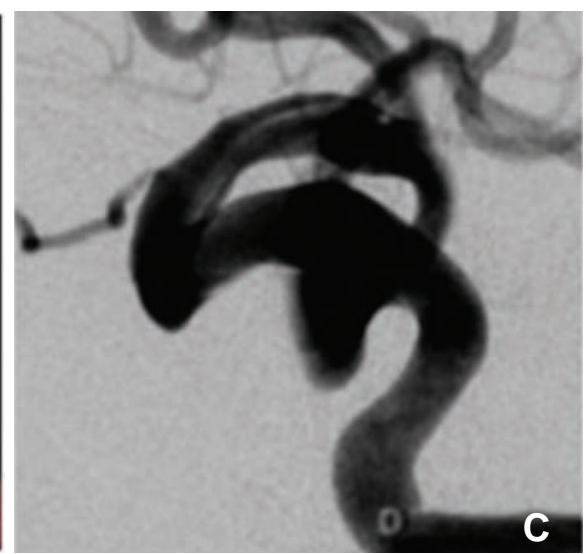

Fig. 3. A case of remaining neck (Case No. 11). Right carotid angiogram showed a large CCA (A). PED was successfully deployed (B), and the postoperative angiogram demonstrated a marked eclipse sign (C). The angiogram 6 months later showed that the aneurysm had diminished in size, but a small remnant neck remained (D, E). A follow-up angiogram at 6 months showed the deviation of the body of PED and an original neck remained as the other pathway (D, E). timing of thrombosis formation. Intra-aneurysmal thrombosis is achieved just after the saccular packing, while it should take some interval to complete the whole thrombosis after the intra-aneurysmal flow stagnation due to the flow diverting effect.

The safety of treatment with PED has recently increased $[11,19]$. In particular, an advanced version of PED, the Flex type, has improved quality and maneuverability thanks to the structural changes, which simplifies and facilitates initial deployment. The pusher wire has been replaced by a larger, elongated hypo-tube to permit better pushability. The Flex type is almost completely re-sheathable due to the introduction of a re-sheath pad [20]. However, the temporary procedurerelated adverse events have not yet been diminished [21]. Previous reports show 4.7 to $6.6 \%$ of patients develop ischemic complications, particularly patients who hypo-respond to anti-platelet agents, and incomplete apposition of PED [14, 15]. We preoperatively checked the effect of anti-platelet therapy for all patients and forced anti-platelet management with additional agents if the result showed insufficient values. Further, we usually added balloon angioplasty to attach the strut to the vessel wall using a balloon catheter $(7 \times 7 \mathrm{~mm})$ (Hyperform ${ }^{\mathrm{TM}}$, Medtronic/ Covidien) in all cases [6]. That is why we did not encounter thrombotic occlusion of the parent artery and branches. However, shortening of PED with deviation into the aneurysmal sac was observed in two cases at follow-up imaging (Case 11, 17), resulting in the remnant neck. These conditions are now carefully observed, and for the case of persistent incomplete occlusion, overlapped FD should be considered. As an inevitable difficulty of a bladed-type stent, an unexpected shortening or elongation can occur depending on the diameter of parent artery. It is important to evaluate and estimate the expected length corresponding to the proper initial and landing position [21].

The use of a flow diverter was more beneficial than the conventional techniques in terms of safety, efficacy and cost compared to the conventional parent artery occlusion and saccular coil packing techniques $[9,18]$. Flow diverters completely seal the aneurysm neck with their diverting effect and lead to aneurysmal thrombosis and shrinkage and support the diseased vessel, allowing its remodeling [22]. The re-establishment of homeostasis may contribute to a favorable angiographic and physical state, and the amelioration of symptoms. 
Although longer follow-up data are essential to precisely determine the efficacy, from a cost-effective and time-saving viewpoint, PED is a relatively safe and reliable method for the treatment of large CCAs.

\section{CONCLUSION}

Flow diverters for large CCAs showed promising clinical and radiological efficacy. They can shrink an aneurysm and improve symptoms without sacrificing the parent artery. It will be necessary to summarize cases and verify long-term results.

\section{References}

1. van Rooij WJ. Endovascular treatment of cavernous sinus aneurysms. AJNR Am J Neuroradiol 2012;33:323-326

2. Chalouhi N, Tjoumakaris S, Dumont AS, Gonzalez LF, Randazzo C, Starke RM, et al. Treatment of posterior circulation aneurysms with the pipeline embolization device. Neurosurgery 2013;72: 883-889

3. Lylyk P, Miranda C, Ceratto R, Ferrario A, Scrivano E, Luna HR, et al. Curative endovascular reconstruction of cerebral aneurysms with the pipeline embolization device: the Buenos Aires experience. Neurosurgery 2009;64:632-642

4. Nelson PK, Lylyk P, Szikora I, Wetzel SG, Wanke I, Fiorella D. The pipeline embolization device for the intracranial treatment of aneurysms trial. AJNR Am J Neuroradiol 2011;32:34-40

5. Saatci I, Yavuz K, Ozer C, Geyik S, Cekirge HS. Treatment of intra-cranial aneurysms using the pipeline flow-diverter embolization device: a single-center experience with long-term follow-up results. AJNR Am J Neuroradiol 2012;33:1436-1446

6. Miyachi S. Tactics, Techniques and Spirits of Neuroendovascular Therapy. - Miyachi 's style, Chapter Skill-A Aneurysm -flow diverter-; Osaka: Medica Shuppan, 2015;164-169. (in Japanese)

7. Roy D, Milot G, Raymond J. Endovascualar treatment of unruptured aneurysms. Stroke 2001;32:1998-2004

8. Puffer RC, Piano M, Lanzino G, Valvassori L, Kallmes DF, Quilici L, et al. Treatment of cavernous sinus aneurysms with flow diversion: results in 44 patients. AJNR Am J Neuroradiol 2014;35: 948-951

9. Zanaty M, Chalouhi N, Starke RM, Barros G, Saigh MP, Schwartz EW, et al. Flow diversion versus conventional treatment for carotid cavernous aneurysms. Stroke 2014;45:2656-2661

10. Briganti F, Napoli M, Tortora F, Solari D, Bergui M, Boccardi E, et al. Italian multicenter experience with flow-diverter devices for intracranial unruptured aneurysm treatment with periprocedural complications--a retrospective data analysis. Neuroradiology 2012; 54:1145-1152

11. O'Kelly CJ, Spears J, Chow M, Wong J, Boulton M, Weill A, et al. Canadian experience with the pipeline embolization device for repair of unruptured intracranial aneurysms. AJNR Am J Neuroradiol 2013;34:381-387

12. Lanzino G, Crobeddu E, Cloft HJ, Hanel R, Kallmes DF. Efficacy and safety of flow diversion for paraclinoid aneurysms: a matched-pair analysis compared with standard endovascular approaches. AJNR Am J Neuroradiol 2012;33:2158-2161

13. Chalouhi N, Tjoumakaris S, Starke RM, Gonzalez LF, Randazzo C, Hasan D, et al. Comparison of flow diversion and coiling in large unruptured intracranial saccular aneurysms. Stroke 2013;44: 2150-2154

14. Becske T, Kallmes DF, Saatci I, McDougall CG, Szikora I, Lanzino G, et al. Pipeline for uncoilable or failed aneurysms: results from a multicenter clinical trial. Radiology 2013;267:858868

15. Kallmes DF, Hanel R, Lopes D, Boccardi E, Bonafé A, Cekirge $\mathrm{S}$, et al. International retrospective study of the Pipeline embolization device: a multicenter aneurysm treatment study. AJNR Am J Neuroradiol 2015;36:108-115

16. Raymond J, Darsaut TE, Kotowski M, Makoyeva A, Gevry G, Berthelet $\mathrm{F}$, et al. Thrombosis heralding aneurysmal rupture: an exploration of potential mechanisms in a novel giant swine aneurysm model. AJNR Am J Neuroradiol 2013;34:346-353

17. Maruta K, Aoki A, Omoto T, Iizuka H, Kawaura H. The Effect of Steroid Therapy on Postoperative Inflammatory Response after Endovascular Abdominal Aortic Aneurysm Repair. Ann Vasc Dis 2016;9:168-172

18. Miyachi S, Ohnishi H, Hiramatsu R, Izumi T, Matsubara N, Kuroiwa T. Innovations in Endovascular Treatment Strategies for Large Carotid Cavernous Aneurysms-The Safety and Efficacy of a Flow Diverter. J Stroke Cerebrovasc Dis 2017;26:1071-1080

19. Guédon A, Clarençon F, Di Maria F, Rosso C, Biondi A, Gabrieli $\mathrm{J}$, et al. Very late ischemic complications in flow-diverter stents: a retrospective analysis of single-center series. J Neurosurg 2016; 125:929-935

20. Miyachi S, Ishii A. Development of a Pipeline-classic Type to Flex: Points of Improvement and Precautions for Use. Journal of Neuroendovascular Therapy 2016;26:1071-1080

21. Park MS, Albuquerque FC, Nanaszko M, Sanborn MR, Moon K, Abla AA, et al. Critical assessment of complications associated with use of the Pipeline Embolization Device. J Neurointerv Surg 2015;7:652-659

22. Kim BM, Shin YS, Baik MW, Lee DH, Lee TH, Kang DH, et al. Pipeline Embolization Device for Large/Giant or Fusiform Aneurysms: An Initial Multi-Center Experience in Korea. Neurointervention 2016;11:10-17 